\title{
Corrosão e proteção catódica de armaduras de aço
}

\author{
LUIZ PAULO GOMES - DIRETOR \\ IEC - InstalaÇões e Engenharia de Corrosão
}

\section{RESUMO}

O CONCRETO, ENQUANTO NOVO E ÍNTEGRO, POSSUI PH ELEVADO E ALTA RESISTIVIDADE ELÉTRICA. ESSAS CARACTERÍSTICAS CONFEREM EXCELENTE PROTEÇÃO CONTRA A CORROSÃO DAS ARMADURAS DE AÇO NELE EMBUTIDAS. COM O PASSAR DO TEMPO, O CONCRETO PODE ABSORVER ÁGUA, CO ${ }_{2}$, CLORETOS, SAIS DIVERSOS, GASES, ÁCIDOS E OUTROS POLUENTES. ESSA CONTAMINAÇÃO REDUZ O PH E A RESISTIVIDADE ELÉTRICA DO CONCRETO, FAZENDO COM QUE ELE SE TRANSFORME EM UM EXCELENTE ELETRÓLITO, PERMITINDO O FUNCIONAMENTO
DAS PILHAS dE CORROSÃo. PARA PROteger as ARMAdURAS NESSES CASOS, A MELHOR SOLUÇÃO, PRÁTICA, EFICIENTE E DE BAIXO CUSTO, CONSISTE NA UTILIZAÇÃO DE ÂNODOS DE PROTEÇÃO CATÓDICA, DESENVOLVIDOS ESPECIALMENTE PARA ESSA FINALIDADE. OS ÂNODOS PODEM SER INSTALADOS DURANTE A CONSTRUÇÃO, DURANTE OS SERVIÇOS DE RECUPERAÇÃO OU NOS CASOS EM QUE A CORROSÃO AINDA NÃO AFLOROU, MAS JÁ FOI DIAGNOSTICADA PELAS MEDIÇÕES DOS POTENCIAIS DAS ARMADURAS.

Palavras-chave: concreto, armadura, aço, corrosão, proteção catódica.

\section{INTRODUÇÃO - PORQUE AS} ARMADURAS SE CORROEM

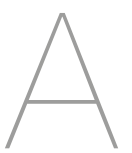

absorção de água, cloretos, $\mathrm{CO}_{2}$, sais diversos, ácidos, gases e outros poluentes é muito comum de acontecer, sendo a principal causa de deterioração por corrosão das obras de concreto.

Os poluentes de um modo geral di- minuem o $\mathrm{pH}$ e a resistividade elétrica do concreto, permitindo que as pilhas de corrosão funcionem com facilidade.

A Figura 1 mostra claramente como tudo funciona.

Pela análise da Figura 1, verifica-se que:

1 - os poluentes penetram no concreto e atingem as armaduras;

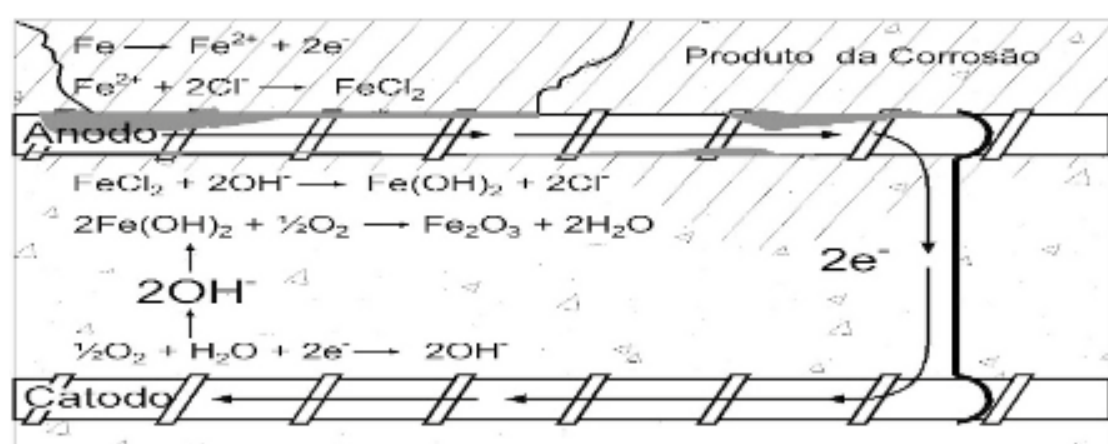

Figura 1

Corrosão do aço embutido no concreto

Fonte: Gomes (2020)
2 - as pilhas de corrosão começam a funcionar;

3 - nas áreas anódicas, o ferro libera elétrons e íons $\mathrm{Fe}^{++}$, começando a se corroer;

4 - os elétrons que chegam nas áreas catódicas reagem com a água e o oxigênio e produzem íons $\mathrm{OH}^{\text {; }}$;

5 - os íons $\mathrm{Fe}^{++}$se combinam com os íons $\mathrm{Cl}^{-}$(quando eles estão presentes) e com os íons $\mathrm{OH}^{-}$;

6 - a combinação do $\mathrm{Fe}^{++} \operatorname{com~O} \mathrm{OH}$ resulta no hidróxido de ferro, que é o produto de corrosão do aço;

7 - o íon cloreto, quando presente, não é consumido na reação e permanece dentro do concreto, reduzindo sua resistividade elétrica, destruindo a passividade do aço e acelerando o processo de corrosão;

8 - o hidróxido de ferro, na presença de água e oxigênio, se converte em hematita, produto de corrosão de cor 


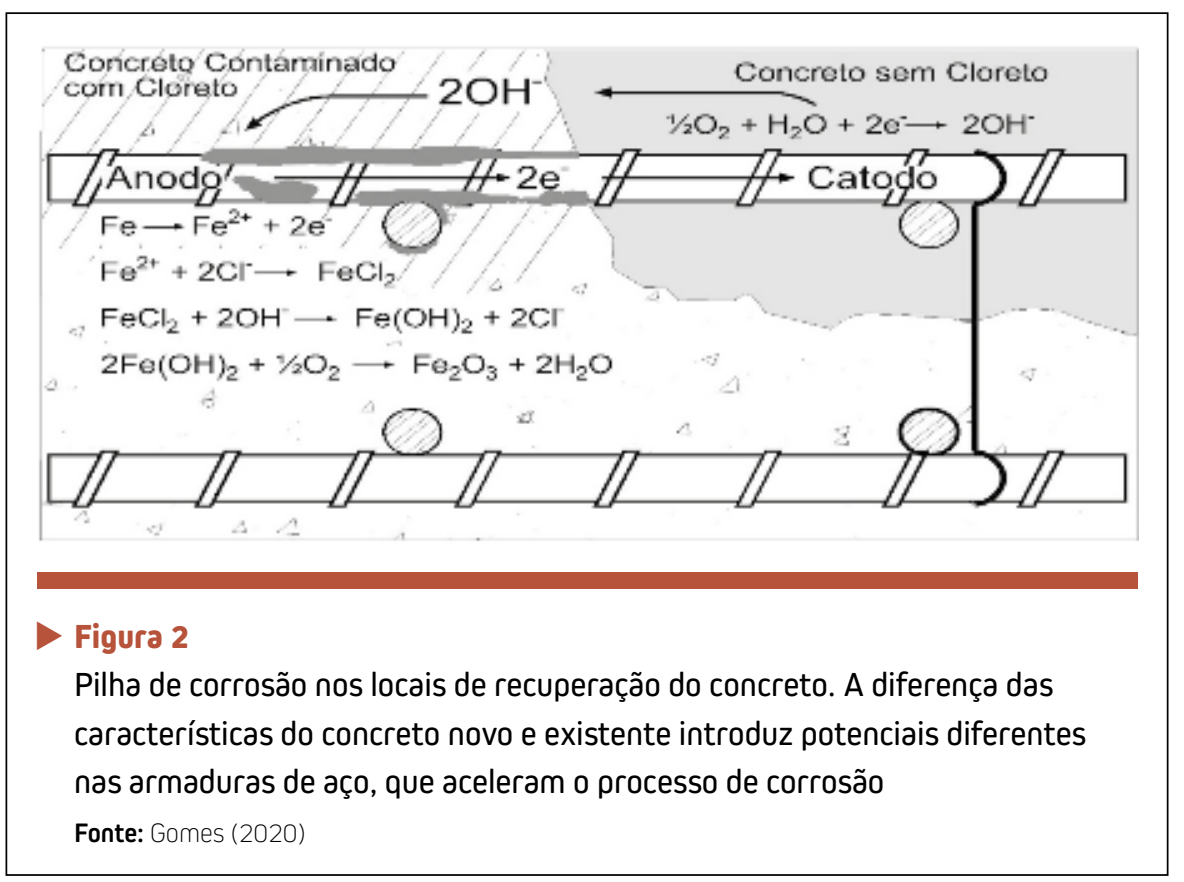

castanho alaranjado, ou em magnetita, produto de corrosão de cor preta esverdeada;

9-o produto de corrosão fica contido no concreto, gerando grandes esforços internos e fissurando a estrutura, permitindo a entrada de mais poluentes e realimentando $\mathrm{O}$ processo de corrosão.

Outra situação acontece quando são executados serviços de recuperação do concreto. A simples diferença das características do concreto novo e do concreto existente, em especial a diferença de resistividade elétrica e do teor de cloretos, dá origem a pontos de potenciais diferentes nas armaduras, que aceleram a circulação das correntes de corrosão, como mostrado na Figura 2.

Essa pilha é uma das mais conhecidas e mais importantes do mundo da corrosão, sendo responsável, também, pela corrosão de tubulações de aço enterradas (oleodutos, gasodutos, alcooldutos, minerodutos, polidutos e adutoras), quando atravessam solos de características e de resistividades elétricas diferentes.

Importante observar que, para que haja corrosão, é necessário a presença de água e de oxigênio, condições sempre presentes nos concretos de um modo geral. Por mais secos que pareçam, os concretos sempre contêm água, em maior ou menor quantidade e sempre possuem oxigênio dissolvido.

Outro aspecto importante é que a corrosão é um fenômeno elétrico, ou mais precisamente um fenômeno eletroquímico. Assim, quando existe corrosão em uma armadura de aço embutida no concreto é porque está havendo uma circulação de corrente elétrica, que é a corrente de corrosão. A melhor maneira de eliminar essa circulação de corrente dentro do concreto e, em consequência, acabar com o processo corrosivo, consiste na instalação dos ânodos de proteção catódica. Os ânodos simplesmente produzem uma circulação de corrente em sentido contrário e de intensidade maior que as correntes de corrosão, eliminando por completo o processo de deterioração do aço.

Sabe-se, também, que a absorção de $\mathrm{CO}_{2}$, muito comum de acon- tecer nas grandes cidades, pode

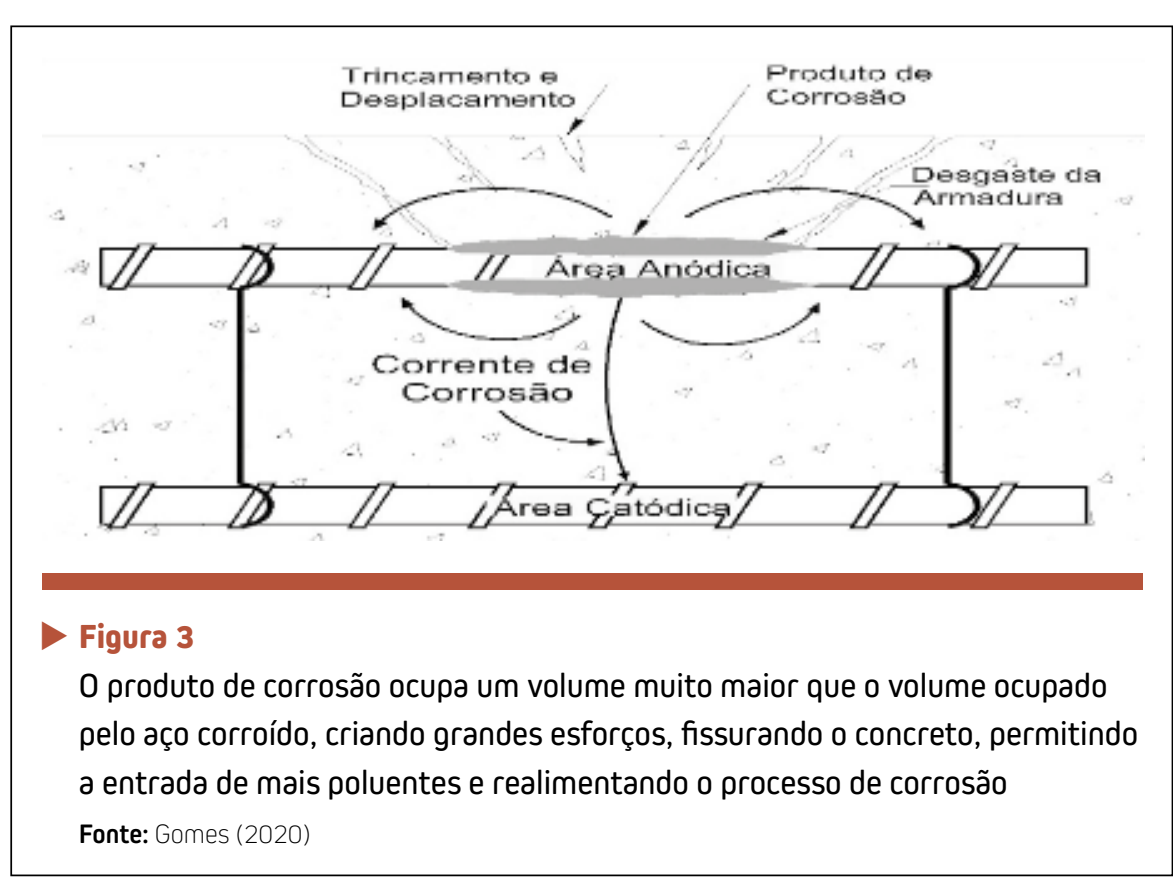


provocar a carbonatação do concreto, diminuindo o seu $\mathrm{pH}$, despassivando o aço e causando sua corrosão, de acordo com a equação 1, bastante conhecida.

\begin{tabular}{|c|}
{$[1]$} \\
$\mathrm{Ca}(\mathrm{OH})_{2}+\mathrm{CO}_{2}(\mathbf{p H}>12)=>\mathrm{CaCO}_{3}+\mathrm{H}_{2} \mathrm{O}(\mathbf{p H}<9)$
\end{tabular}

Importante observar que, em todas essas situações, o produto de corrosão formado ocupa um volume muito maior que a massa de armadura corroída, gerando grandes esforços e fazendo com que o concreto fissure, permitindo a entrada de mais poluentes, alimentando o processo de corrosão (Figura 3).

É bastante comum a ocorrência de estruturas de concreto (industriais, marítimas, portuárias, urbanas ou residenciais) com trincas e fissuras importantes causadas por esse fenômeno.

Com relação a isso, é muito importante lembrar que as trincas de um

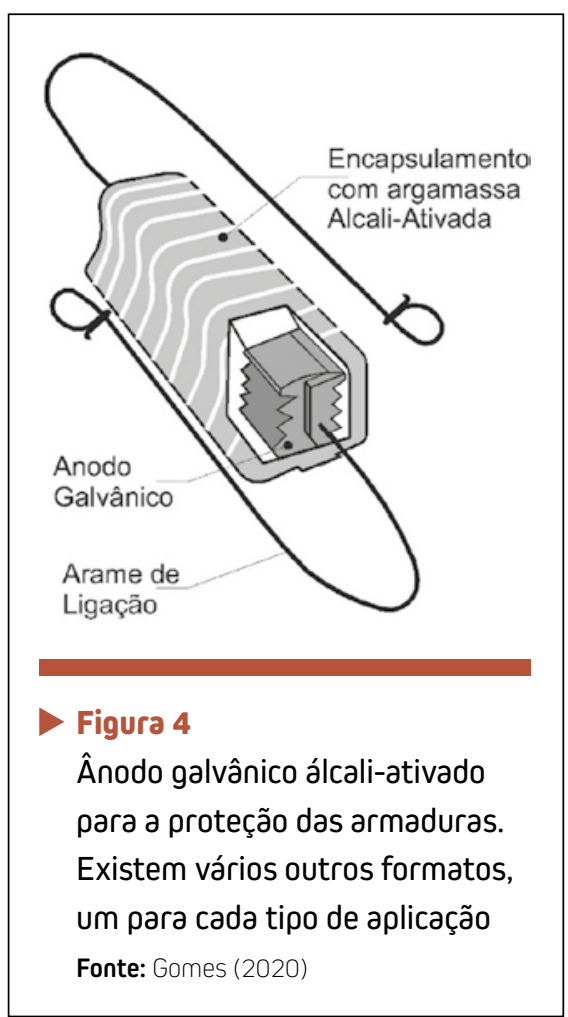

modo geral são a porta principal de entrada dos poluentes e, por isso, devem sempre ser vistas com preocupação e evitadas na medida do possível. Para que uma estrutura possa conviver com as trincas, em especial nos locais contaminados por cloretos, a instalação dos ânodos de proteção catódica é de fundamental importância.

\section{COMO PROTEGER AS ARMADURAS DD AÇO}

Para proteger as armaduras contra a corrosão, a melhor solução consiste na utilização dos ânodos galvânicos de proteção catódica, constituídos de uma liga de zinco de alto potencial, fabricados especialmente para essa finalidade.

Esses ânodos, álcali-ativados, são fornecidos com um encapsulamento de argamassa apropriada de $\mathrm{pH}$ elevado, superior a 14, com a finalidade de mantê-los permanentemente ativados dentro do concreto. A diferença de potencial entre o ânodo e o aço dá origem a uma corrente elétrica de proteção, que sai do ânodo e atinge a ferragem,

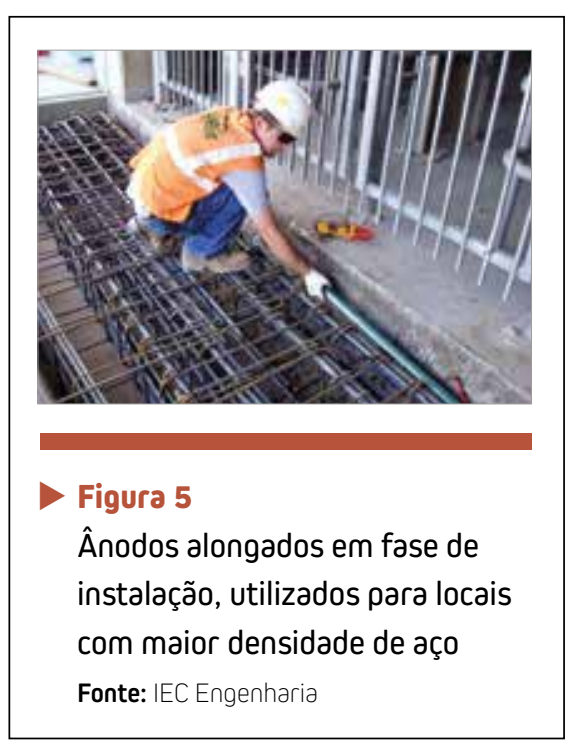

modificando suavemente o seu potencial, aumentando o $\mathrm{pH}$ do concreto e eliminando as pilhas de corrosão.

A Figura 4 mostra um desses ânodos, destacando-se a alma de zinco de alto potencial, o encapsulamento álcali-ativado e os arames de fixação.

Em determinadas aplicações, em especial onde a densidade de aço é mais elevada, utiliza-se um outro formato de ânodo, mais alongado e que utiliza a mesma alma, o mesmo encapsulamento álcali-ativado e os mesmos arames de fixação. A Figura 5 mostra a instalação de um desses ânodos alongados.

A instalação dos ânodos é muito fácil de ser feita, uma vez que eles são simplesmente amarrados às armaduras (Figura 6), tomando-se o cuidado de verificar a continuidade elétrica da ligação.

A vida útil dos ânodos poder ser calculada com facilidade e pode ser definida pelo projetista, mediante a escolha adequada do tipo e da quantidade de ânodos.

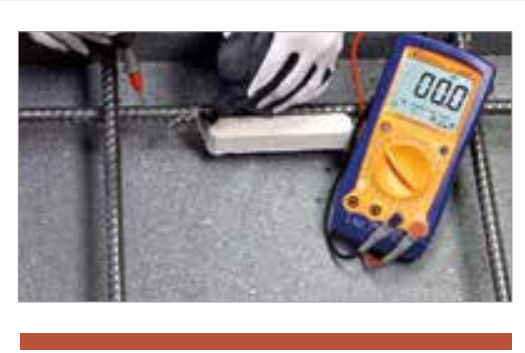

Figura 6

Exemplo de instalação do ânodo e do teste para a verificação da continuidade elétrica entre 0 ânodo e a armadura de aço

Fonte: IEC Engenharia 


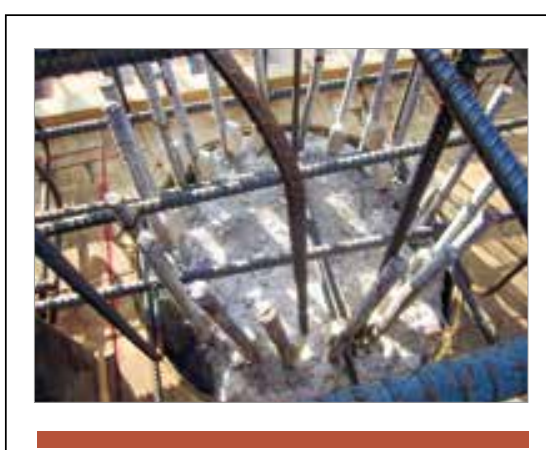

Figura 7

Instalação dos ânodos em uma obra nova, durante a construção, nos locais onde sabidamente 0 concreto poderá absorver água, cloretos e poluentes com o passar do tempo

Fonte: IEC Engenharia

\section{QUANDO INSTALAR OS ÂNODOS}

Os ânodos podem ser instalados em três situações diferentes.

\section{I Instalação dos ânodos em estruturas novas, durante a construção}

Em todos os casos onde se sabe que, com o passar do tempo, o concreto poderá absorver poluentes, em especial locais úmidos e contaminados com cloretos, como nas estruturas próximas ao mar, a instalação dos ânodos deve sempre ser feita durante a construção, por ocasião da armação das armaduras e antes da concretagem. Nesses casos o dimensionamento é muito econômico, uma vez que em estruturas novas, na fase de construção, pode-se utilizar densidades mais baixas de corrente. Quando instalados em obras novas, os ânodos ficam hibernando dentro do concreto e

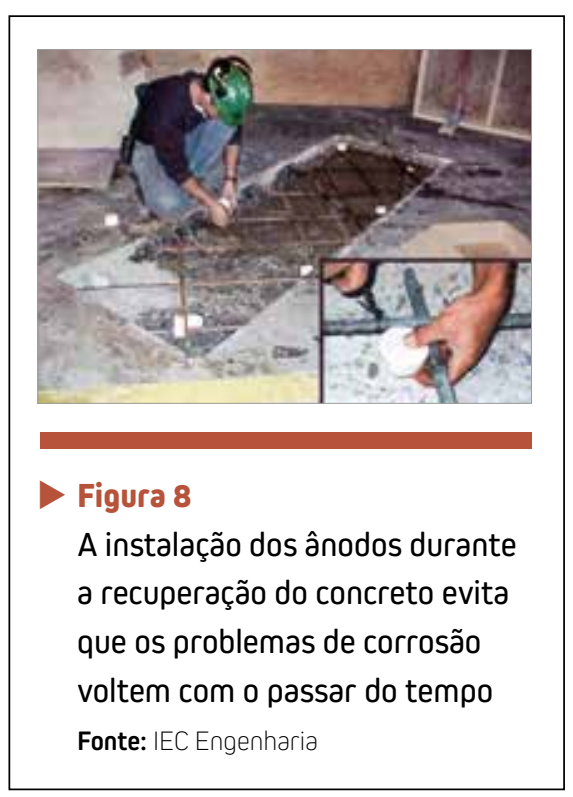

somente começam a funcionar quando e onde a umidade e os poluentes começam a atingir as armaduras, evitando que a corrosão se inicie e garantindo vida longa à estrutura, permitindo o atendimento aos requisitos da Norma ABNT 15575:2013 no que diz respeito à vida útil das edificações habitacionais.

A Figura 7 mostra um exemplo dessa aplicação.

\subsection{Instalação durante os trabalhos de recuperação do concreto}

Nos serviços de recuperação, a interface entre o concreto antigo e o concreto novo adiciona pilhas importantes de corrosão às armaduras. A instalação de ânodos galvânicos nessas regiões é de fundamental importância para evitar que novos e mais severos problemas de corrosão aconteçam. Deve-se sempre aproveitar esse momento em que as armaduras estão expostas e instalar os ânodos de proteção catódica, com facilidade e baixo custo, evitando-se a reincidência dos problemas de corrosão.

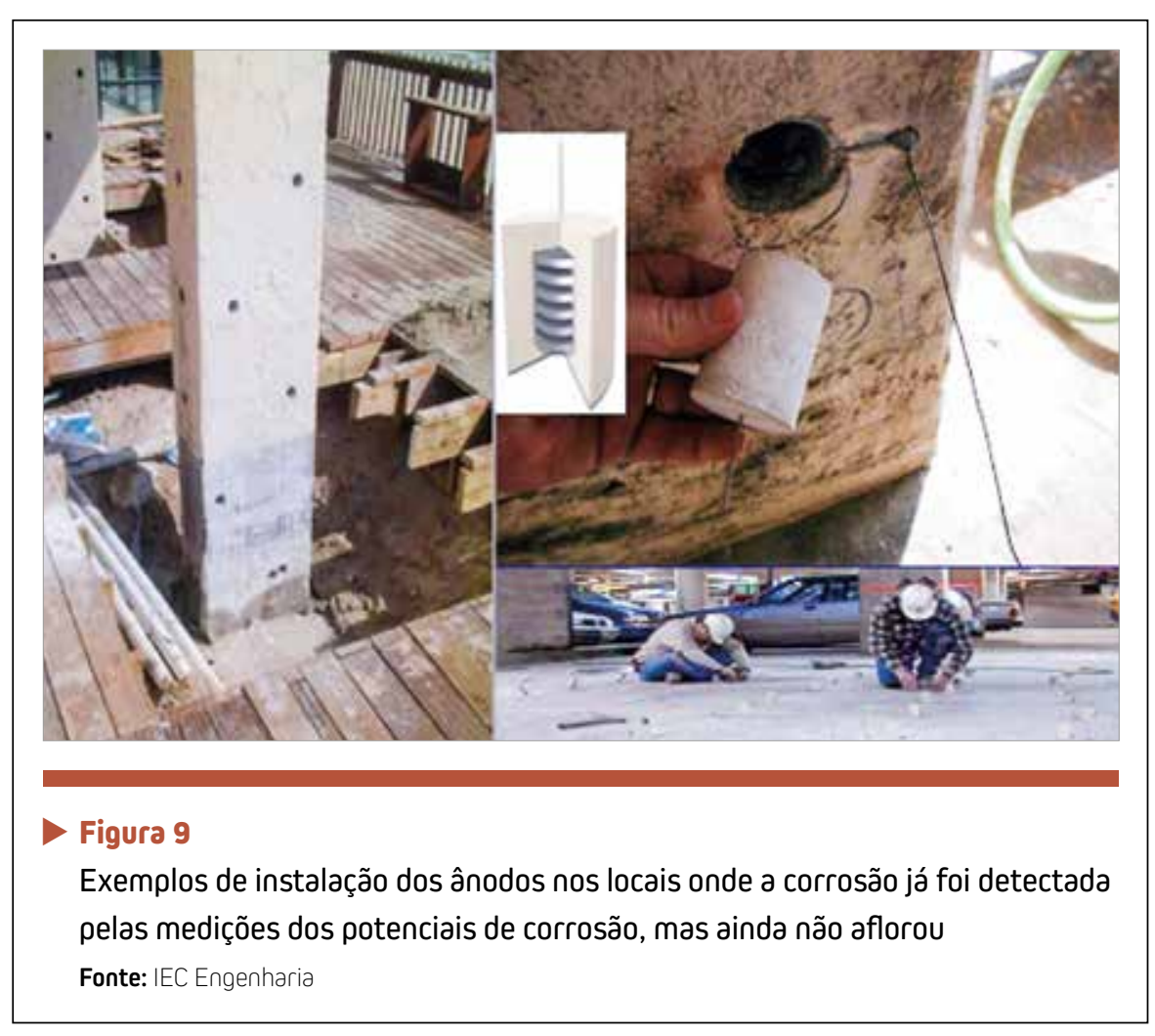




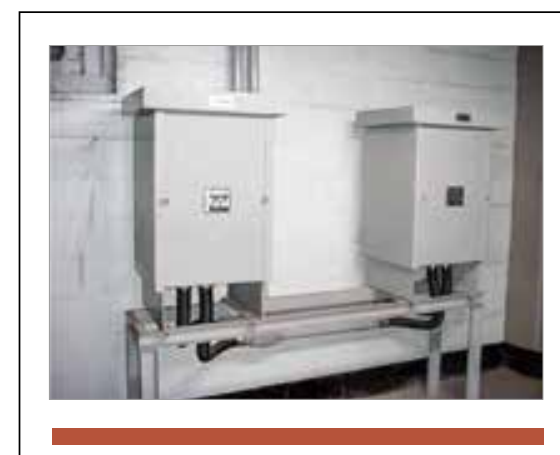

Figura 10

Retificadores de corrente utilizados nos sistemas por corrente impressa. 0 terminal negativo é ligado nas armaduras e o terminal positivo é ligado nos ânodos inertes, que podem ser cilíndricos ou em forma de tela Fonte: IEC Engenharia

\subsection{Instalação nos locais onde} os efeitos da corrosão ainda não são evidentes

Os ânodos também posem ser instalados sem que as armaduras es-

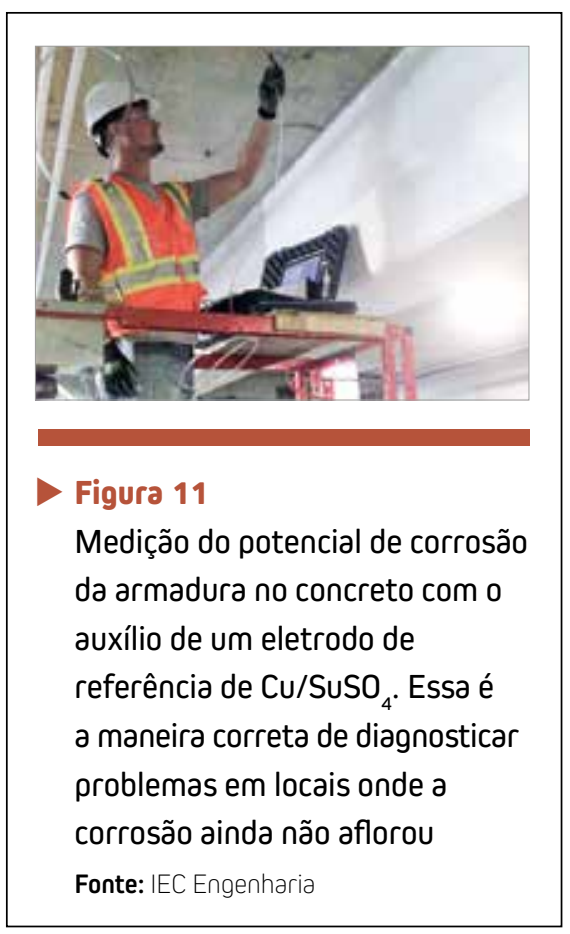

tejam expostas e sem a necessidade de fragilizar o concreto. Isso acontece com muita frequência em vigas, pilares, elementos de fundação, pisos e tetos, onde são diagnosticados problemas de corrosão por meio de medições dos potenciais das armaduras. Nesses casos são feitos pequenos furos na estrutura de concreto para a instalação de ânodos cilíndricos, especialmente desenvolvidos para essa finalidade, conforme mostrado na Figura 9.

\section{PROTEÇÃO CATÓDICA POR CORRENTE IMPRESSA}

Para o caso de grandes estruturas, o sistema de proteção catódica mais indicado pode ser o sistema do tipo por corrente impressa, onde são utilizados ânodos inertes especiais alimentados por um ou mais retificadores de corrente (Figura 10).

A definição do método mais indicado de proteção catódica (galvânica ou por corrente impressa) depende de um estudo criterioso, onde são analisadas as vantagens técnicas e econômicas de cada um deles, para cada caso em particular.

\section{MEDIÇÕES DOS POTENCIAIS DE CORROSÃO DAS ARMADURAS}

Para a avaliação e estudo de corrosão, utiliza-se sempre a análise dos potencias de corrosão das armaduras no concreto, medidas com o auxílio de um voltímetro de alta impedância e um eletrodo de referência de $\mathrm{Cu} / \mathrm{CuSO}_{4}$, de acordo com a Norma ASTM C876-15 (Standard Test Method for Corrosion Potentials Un- coated Reinforced Steel in Concrete), conforme mostrado na Figura 11. Nesses casos, as seguintes situações podem ocorrer:

potencial armadura/concreto mais negativo que $-350 \mathrm{mV}$ (alto risco de corrosão);

potencial armadura/concreto entre -350mV e -200mV (médio risco de corrosão);

potencial armadura/concreto menos negativo que -200mV (baixo risco de corrosão).

\section{NORMAS TÉCNICAS}

Ainda não existem normas brasileiras para a aplicação de proteção catódica em estruturas de concreto. As normas técnicas internacionais mais utilizadas nos projetos, especificações e serviços de instalação, tanto dos sistemas galvânicos quanto dos sistemas por corrente impressa, são as seguintes:

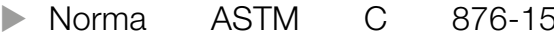
Standard Test Method for Corrosion Potentials Uncoated Reinforced Steel in Concrete;

Norma ISO12696:2016 Cathodic Protection of Steel in Concrete;

Standard NACE SP0187-2017 Design for Corrosion Control of Reinforcing Steel in Concrete;

Standard NACE SP0112-2017 Corrosion Management of Atmospheric Exposed Reinforced Concrete Structures;

Standard NACE SP0290-2007 Impressed Current Cathodic Protection of Reinforcing Steel in Atmospherically Exposed Concrete Structures; 
> Standard NACE SP0408 Cathodic Protection of Reinforcing Steel in Buried or Submerged Concrete Structures.

\section{PROCEDIMENTO}

O procedimento recomendado para o estudo, projeto, fornecimento e instalação do sistema de proteção catódica em estruturas de concreto é o seguinte:

> primeira etapa: análise dos desenhos, inspeção visual, medições dos potenciais das armaduras e demais medições de campo;

> segunda etapa: análise das informações de campo e elaboração do projeto de proteção catódica, com definição do tipo de proteção a ser utilizado (galvânico ou corrente impressa), especificação dos ânodos, desenhos e instruções de instalação;
> terceira etapa: fornecimento e instalação dos ânodos, incluindo os Certificados de Garantia.

\section{CONSIDERAÇÕES FINAIS}

Os problemas de corrosão em estruturas de concreto são bastante frequentes e precisam ser estudados criteriosamente, sendo importante que sejam diagnosticados de forma correta.

A utilização de proteção catódica com o uso de ânodos galvânicos (proteção catódica galvânica) ou com ânodos inertes e retificadores de corrente (proteção catódica por corrente impressa) é a uma solução muito importante, que permite garantir resultados confiáveis ao longo dos anos, sendo uma ferramenta de fundamental importância na tarefa de prolongar a vida útil das estruturas de concreto.
A instalação de proteção catódica pode ser complementada com outros métodos de proteção, como a utilização de concretos especiais, aditivos, polímeros, revestimentos, galvanização das armaduras e outras técnicas, mas pode também ser utilizada isoladamente, com segurança e total garantia, sem a utilização de qualquer outra medida de proteção.

A instalação de ânodos galvânicos é sempre recomendada nas atividades de recuperação do concreto como uma solução definitiva para os casos onde o concreto já foi contaminado e a corrosão já iniciou.

Em todas as situações e em especial nos locais onde a corrosão ainda não aflorou, as medições dos potenciais das armaduras são de extrema importância para um diagnóstico preciso, seguro e conclusivo.

\section{DREFERÊNCIAS BIBLIOGRÁFICAS}

[1] GOMES, L.P.. Sistemas de Proteção Catódica. Rio de Janeiro, Editora Interciência Segunda Edição, , 2020, 351 Páginas.

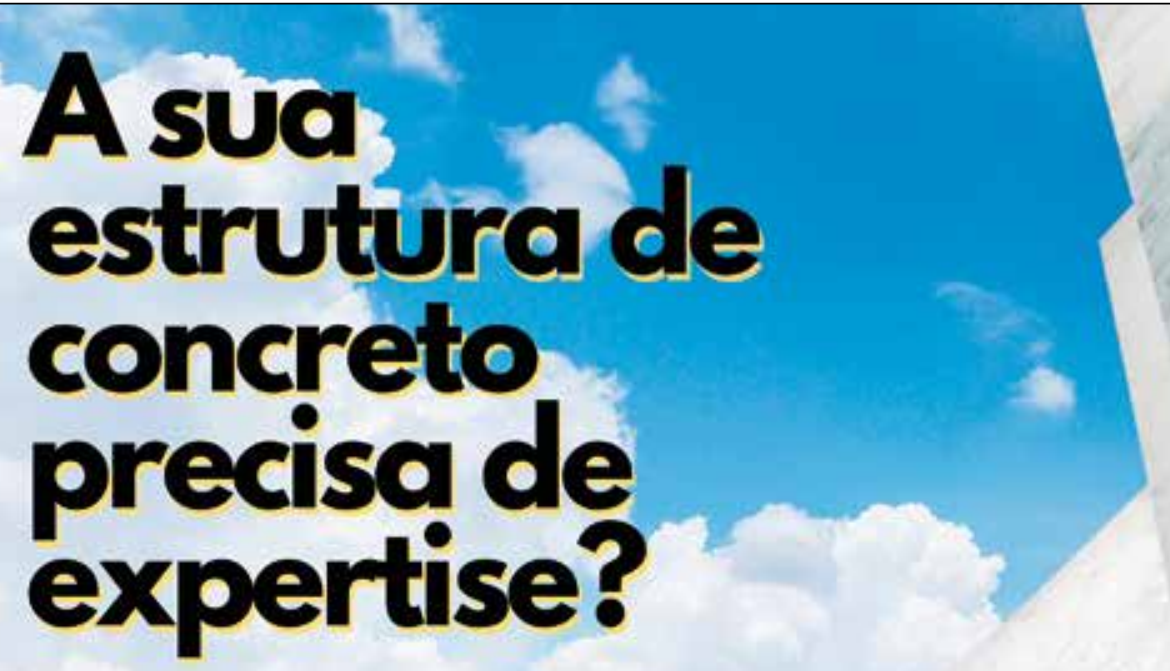

CONTE COM QUEM É PhD NO ASSUNTO.

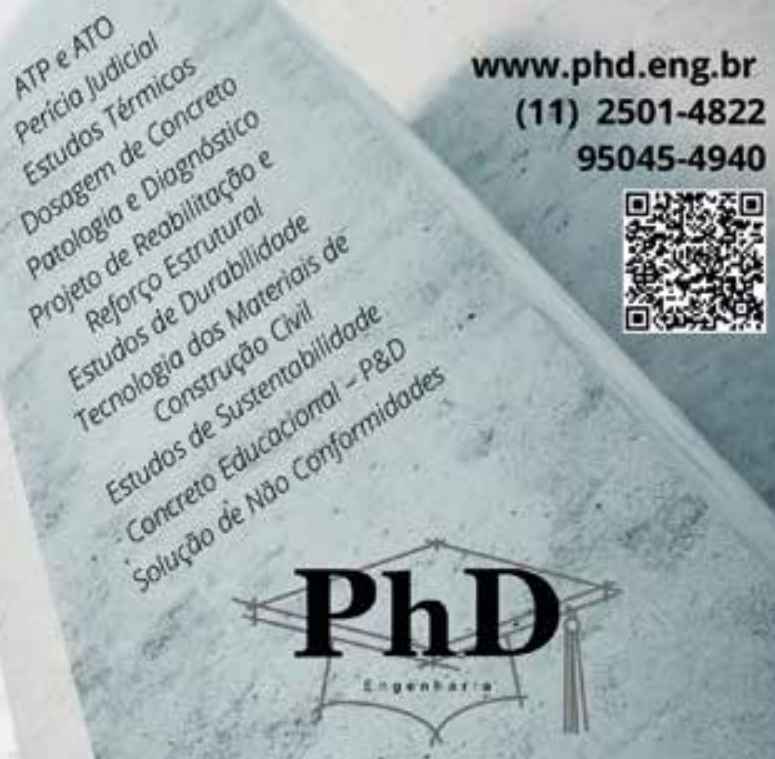

"do Laboratório de Pesquilsa ae Canteiro de Obros" 